Rethinking Responsible Agency in Corporations: Perspectives from Deleuze \& Guattari

\author{
Mollie Painter-Morland (PhD) \\ Department of Philosophy \\ De Paul University \\ 2352 North Clifton Avenue \\ Chicago, IL 60614-3208 \\ and \\ University of Pretoria \\ Pretoria, 0002 \\ South Africa
}

mpainter@depaul.edu 


\title{
Rethinking Responsible Agency in Corporations: Perspectives from Deleuze \& Guattari
}

\begin{abstract}
:
The notion of "responsibility" can be understood in a number of different ways, namely as being accountable for one's actions, as a personal trait, or as a task or duty that results from one's role. In this paper we will challenge the assumptions that underpin each of these employments of the word "responsibility" and seek to redefine the concept as such. The main thrust of the argument is that we need to critically interrogate the idea of "identity" and deliberate decision-making that inform the use of all three of these notions of "responsibility". By drawing on selected concepts emanating from the oeuvre of Gilles Deleuze and Félix Guattari, our understanding of agency moves away from "identity" towards "multiplicity". In fact, it will be argued that our sense of "agency" is a side-product of our own desiring-production as it operates in and through our interactions with other human beings and organizational structures. The paper therefore contends that "responsible management" requires ongoing re-articulations of moral responsiveness.
\end{abstract}

Keywords: Agency, responsibility, Deleuze and Guattari

JBE Category: Philosophical foundations 


\section{3}

\section{RETHINKING RESPONSIBLE AGENCY IN CORPORATIONS: \\ PERSPECTIVES FROM DELEUZE \& GUATTARI}

\section{INTRODUCTION:}

The notion of "responsibility" can be understood in a few different ways (Takala and Pallap, 2000, p.110). In the first place, it can be employed to indicate accountability, for instance when we claim that a corporation is responsible for environmental damage. Secondly, it can refer to a character trait, i.e. when we call someone a "responsible" person. In the third place, we use the notion of responsibility to assign specific roleresponsibilities to individuals or entities. In each of these three employments of the term "responsibility", a certain understanding of identity and agency is operative. Without acknowledging and challenging these common conceptions, we will not be able to fully understand and meet the challenges of responsible management. ${ }^{1}$

In this paper, we trace various theoretical perspectives on responsibility as we encounter it Business ethicists' employment of agency theory. Within Business Ethics, agency theory operates in many different areas, for instance within corporate governance, the discussion of corporate culture, and in corporate citizenship discourses. The concept of "agency" can be used in a variety of ways, but it mostly refers to the duty that corporate agents, in most cases managers, have to serve the interests of their principals. Agency can also be more broadly defined as the capacity to make decisions and act on

\footnotetext{
${ }^{1}$ I would like to thank the anonymous reviewers, as well as the editors of this Special issue, for their generous comments and suggestions, which allowed a much clearer argument to emerge. I would also like to thank Rene ten Bos for encouraging me to be brave enough to draw on Deleuze and Guattari's oeuvre in my business ethics research.
} 
these decisions, even amidst certain institutional constraints. Within business ethics, the discourses make reference to both individual agency and to broader "collective agency", such as that of a corporation as a whole, or of structure, such as a board of directors. What will become evident, is that a belief in the possibility of cultivating a specific individual and corporate identity underpins much of agency theory. When "agency" is assigned to individuals or corporations, we assume a certain decision-making capacity, strongly linked to a belief in the necessity of sound individual or corporate "character". We tend to assume that certain ethical "traits" can be cultivated within individuals and that corporations can proactively manage their "ethical cultures". Even "corporate citizenship" discourses again assign corporations certain functional identities (Moon, Crane and Matten, 2005; Crane, Matten, Moon, 2004). In these discourses, the question of who or what these "agents" really are and how they come into being, is avoided. In the absence of this ontological discussion, it becomes difficult to sustain claims regarding the procurement of a "moral identity" within individuals or corporations.

In recent years, a number of authors have criticized the tendency within Business Ethics research to offer practical advice to business practitioners, instead of engaging in the more complex ontological questioning that a true commitment to ethics requires (See in this regard Bevan and Corvellec, 2007). It has been argued that in its preoccupation with solutions, Business Ethics loses its critical edge, and perpetuates some assumptions that make it impossible to understand the nature of ethical wrongdoing in a business context (Parker, 1998). Within the Critical Management literature, much of this work has been pursued, but for some reason these insights have not been incorporated into mainstream Business Ethics, with some notable exceptions (Clegg \& 
5

Rhodes, 2006; Jones, Parker and ten Bos, 2007; Werhane and Painter-Morland, 2007;

Painter-Morland and ten Bos, 2011). For instance, there have been a number of attempts

to introduce poststructuralist insights into the nature of subjectivity into management and organizational studies literature. This research indicates that ethical directives that assume the existence of an isolated, principled transcendental subject will fail because it underestimates the complexity of human motivation and the relational nature of normative orientations and ethical risk (Painter-Morland, 2009; Boholm \& Corvellec, 2011). Another strain of this research focuses on the value of ethical codes and compliance initiatives. Though there is acknowledgement of the need for such initiatives, an overreliance on codification tends to undermine the unique moral responsiveness that should be central to ethical deliberation. If this kind of individual ethical questioning is foreclosed, the ethical moment is lost (Bauman, 1993; Roberts, 2003; Bevan \& Corvellec, 2007; Painter-Morland, 2010).

This paper extends the work done in this broad area by furthering an ontological inquiry into what agency means in a business context and considering the implications this may have for our conception of accountability and responsibility. We draw on a selection of concepts generated by Deleuze and Guattari in order to challenge some of the assumptions of agency theory, to reframe our understanding of responsible management, and to reconsider the implications of this reframing in practice. ${ }^{2}$ We seek to redefine human motivation from a more materialist perspective by illustrating how agency

\footnotetext{
${ }^{2}$ Deleuze and Guattari's oeuvre spans a wide variety of texts, and includes a large array of new concepts, all of which is impossible to deal with in this article. A selection has therefore been made based purely in my contention that some of these concepts offer productive challenges towards our understanding of agency and responsibility. It is indeed the case that some of their other concepts can be very helpful as well, as I try to illustrate in my ongoing research.
} 
emerges as a side-product of our human pursuits, or in the words of Deleuze and Guattari, our desiring-production. We will see that this reality has implications for our attempts at containment and control within a business context. Since we are constantly engaged in processes of structuring and destructuring within our corporate environments, it is only in a thoughtful engagement with this ongoing process that we act as "responsible" agents. From this perspective, it becomes necessary to redefine responsibility as a commitment to ongoing responsiveness to changing environments, rather than as some fixed role or trait.

\section{RESPONSIBILITY AS ACCOUNTABILITY:}

One of the most important ways in which responsibility is discussed within Business Ethics relates to whether we can hold corporations and their agents accountable for wrongdoing or ethical failures. In order for a firm or an individual to be held accountable, the issue of agency has to be addressed, i.e. who/ what made the decision and took the actions that had specific consequences. In terms of corporate agency, an additional question regarding the principal-agent relationship is also posed: On behalf of whom are the actions taken - shareholders, or stakeholders? Is the motive mere profit, or the benefit of all stakeholders who may be impacted by the actions of the firm? We will refrain from rehashing the popular Friedman (1970) versus Freeman (1984) debate here. It can safely be said that over the past 25 years, the stakeholder perspective won out over a single-minded concern for shareholder profit (Freeman, Harrison, Wicks, \& De Colle, 2010). But even when one can establish that most corporations do have an interest in being responsible towards a broad range of stakeholders, and not just stockholders, many 
7

other issues remain unresolved. The question of who exactly made the decision that caused either benefit or harm to stakeholders is oftentimes difficult to answer. For example, we would think that decisions are typically made by an individual, be it a senior manager, or the CEO, but in the case of corporate misconduct, there are often more people involved in the decision-making process. Where do responsibility and accountability ultimately reside?

Like the stakeholder versus stockholder debate, the discourse on corporate moral agency is well-trodden ground within Business Ethics and we will not rehearse it all here. A few brief issues however have to be revisited in order for us to understand the implications of agency theory for responsible management. The first question that confronts us is whether a corporation can make decisions or have intentions in the way that individual human beings do. Ever since the emergence of Business Ethics as a discipline many decades ago, there has been much debate around this issue. The most prominent theory in this regard was developed towards the end of the 1970's by Peter French who argued that corporations are moral agents in much the same the way that individual human beings are, because they can intend actions and therefore have to be held accountable for those decisions. They have great powers in society, and so it is in all of our interests that we do hold these corporations accountable.

French (1984) also argued that they have the capacity to make rational decisions through what he termed corporate internal decision-structures (CID-structures), and that they can revise these rational decisions over time. Initially, he argued that these structures resemble the beliefs and desires of those of human beings, but this position received much criticism. Corporations do not have bodies that can be hurt or desires that need to 
be fulfilled, so surely one could not argue that corporations are similar to human beings in anything but a metaphorical sense.

Some of French's critics argued that he was committing the basic philosophical fallacy of anthropomorphism, i.e. ascribing some human characteristic to non-human entities. French (1995) subsequently refined his position by arguing that corporations have intentions not because they are persons but because they have a capacity for moral agency. This means that corporations can have intentions in the sense that they are capable of planning for future events and acting on those plans. They therefore operate as agents even though they are not persons.

There have been a number of attacks against the notion of "corporate personhood". In this regard, Bobby Banerjee's (2007) discussion of the evolution of corporate entities over the last two centuries offers us valuable perspectives. Banerjee makes it clear that the corporation as we know it today does not resemble the role that was originally envisaged in the emergence of these entities in the 1800's. At that time, the state could revoke the charter of a corporation if it did not act in the interest of the public good, and it often did so. By the $20^{\text {th }}$ century however, these restrictions on corporations have all but disappeared. It was not until the 1960's and 1970's that environmental and consumer activists started campaigning again for a system of federal charters to reign in the power of corporations. Given how the legal persona of the corporation has evolved, this has been easier said than done. Corporations are no longer officially required to serve the public interest, and even though some laws govern their relationships with stakeholders, the law also grants them many rights and freedoms. So 
9

much so, that some have argued that the rights and freedoms of the corporation as a

"legal person" sometimes trump those of human persons. How did this happen?

Banerjee indicates that it was the landmark court decision of Dartmouth College v. Woodward in 1819 that bestowed property rights on corporations. Legal counsel for Dartmouth Corporation argued that the rights of private corporations should be protected from the changes and fluctuation of political opinions and parties. This led Chief Justice of the United States, John Marshall, to conclude that “...a corporation is a legal person" or an "artificial legal entity" distinct from its owners and officers. This decision had important ramifications. It meant that the corporation was no longer perceived as a creation of the state that should serve the public interest and that it had similar private rights as individuals. For instance, as an artificial legal person the corporation is entitled to protection under the $14^{\text {th }}$ Amendment of the US Constitution. The $14^{\text {th }}$ Amendment affords all persons under the state's jurisdiction equal protection, and as such, may in certain cases pit the protection of corporate "persons" against that of flesh and blood human beings. These more practical consequences caution us to engage in a more thorough philosophical interrogation of how agency operates within the corporate realm, and to anticipate its consequences for responsible management.

What becomes evident in the treatment of agency theory in Business Ethics, is the reliance on the idea that corporations and their agents can be held accountable, based on the decisions they make and the actions they take. It therefore assumes that a specific entity goes through a deliberate moral decision-making process that has certain consequences, based on certain moral values or principles. But is this indeed how valuation takes place within the corporate realm? 
We will interrogate this question from the perspective of Deleuze and Guattari. In “Anti-Oedipus: Capitalism and Schizophrenia" (1992/1983), Gilles Deleuze and Félix Guattari offer a critical analysis of the way in which capitalist practices come into existence. They retrace the origins of both corporations and individuals back to the basic flows of desire that make up the world. The social orders of which we are part can be traced back to the flow of desire that bring us as individuals into interaction with other individuals and entities. All the entities associated with capitalism are related to some of the most basic workings of the human unconscious. Deleuze and Guattari describe this as "desiring-production", a neologism for a conception of desire infused with production (Buchanan, 2008, p. 43). Desire is therefore not to be understood as a lack, but instead as a productive force that brings about everything that we come to know as "persons" "institutions" or "things". As such, desire constitutes the very infrastructure of daily life (Buchanan, 2008, p. 39).

In Deleuze and Guattari's work, desire should not be understood merely as sexual desire, which should be seen as just one manifestation of the various flows that allow us to connect with other human beings and with other animate and inanimate entities. As Bonta and Protevi (2004, p. 76) describe it, Deleuze and Guattari's notion of desire refers to "the material process of connection, registration and enjoyment of the flows of matter and energy coursing through bodies in networks of production of all registers, be they geologic, organic, or social." Within each one of us, there are multiple flows and desires, which connects spontaneously with other human beings, with animals, objects, and with institutions. These connections create "couplings", which in turn start to shape various coded territories. In Deleuze and Guattari's vocabulary, "territorialization" refers to the 


\section{1}

process by which we as human beings organize our world into spatial patterns such as ‘inside' versus 'outside', or 'center' versus 'periphery'.

The territories that are shaped in and through the processes of desiring production provide the spatial, material and psychological components that constitute a society, group, or individual. However, rather than being a sedentary place with fixed borders, the territory is itself a malleable site of passage (Message, 2005:275). In fact, territorial assemblages can be described as a mobile and shifting centre. Our economic activities therefore have to be understood as one manifestation of this desiring-production and the coding and recoding dynamics that are part of this. As we connect with each other and with things in the world, the territories that are created are always in the process of being deterritorialized and reterritorialized. It is important to understand that territorialization, deterritorialization and reterritorialization presuppose each other. Deterritorialization is the possibility of change and transformation that is part of any territory (Parr, 2005, p. 67).

Deleuze and Guattari highlight capitalist production as the way in which decoding and deterritorialization conspire to define our civilization (Deleuze \& Guattari, 1983, p. 244). This makes capitalism a formidable "desiring machine". The social and technical structuring, de-structuring and restructuring within capitalism reveal the desiringproduction we are all necessarily engaged in. Deleuze and Guattari are of course very critical of how capitalism came to be the social and economic form that our desiringproduction takes. The reason for this lies in how this deterritorialization and reterritorialization play out in capitalism. To say that capitalism is characterized by "constant deterritorialization" means that capitalism typically disrupts some of the coded 
societal orders upon which our sense of self and security has been built. For example, within a coded social system, the prohibition on sex before marriage is something that signifies the stability of family life and procreation in society. Within a capitalist system, sex becomes a commodity to be sold or to be used to sell other commodities. Some other examples that Deleuze and Guattari mention are: the deterritorialization of wealth through monetary abstraction; the decoding of the flows of production through merchant capital, and the decoding of States through financial capital and public debts. As such, it would seem that capitalism frees up our coded existence and creates new possibilities.

However, this is not where the process ends. Capitalism replaces "codes" with "axioms". This axiomatization empties flows of the specific social meaning that codes conveyed, and replaces it with a structure within which everything can be made equivalent based on its monetary value. When the axiomatic enters, it becomes very difficult, if not impossible to change our understanding of certain "entities" and "identities". So much so that it becomes impossible to critically scrutinize certain practices. How does this happen? Industrial capital leads to the conjunction of all the decoded and deterritorialized flows in taking control of production and driving it towards creating a surplus value. This surplus has to be sold and this can only happen if our desire can be directed at some new kind of "value". The problem is that production of surplus value leads to a system in which "money begets money" (Deleuze \& Guattari, $1992 / 1983$, p. 227). The belief that profit is valuable in and of itself starts to function as an axiomatic universal truth, which structures everyone and everything in its path to perpetuate this truth. In this process, "value" no longer refers to any actual valuable "thing", but becomes something with a substance, life and motion all of its own. "Value" 
13

no longer designates the relations of commodities, but enters into relations with itself.

Under these conditions, capitalism functions as a diachronic machine that organizes all the decoded flows for its own purposes. The profitability of the firm and its relationship to the market and with commercial and financial capital requires more and more machinic surplus value to fuel its pursuit of value for the sake of value. In this process, both physical labor and "knowledge capital" (specialized education and information) become part of capitalism's machinic operations. Human beings become part of capitalism's machinery.

From this perspective, it becomes possible to consider that it is precisely capitalism's facility for decoding and unleashing flows, and its tendency to pursue value for the sake of value, that compromises responsible management. In many cases the actual corporate entities involved are afforded only a fleeting existence, and responsibility for the human beings involved in its operations is avoided. Because the criteria for anything of value is more value, entities that were created for the purposes of value generation, like corporations, have no inherent right to existence. In fact, since these "entities" have been produced merely as a means to an end, they can easily be replaced, along with those associated with them. As Ian Buchanan explains, Deleuze and Guattari's analysis of the life of capital allows us to appreciate the precariousness of corporate entities. By seeking out more profitable investment vehicles and lucrative opportunities elsewhere, capital thrives even when giant companies like Microsoft don't (Buchanan, 2008, p. 57).

What we have to understand to get as sense of the precariousness of entities in a world characterized by advanced capitalism, is that the kind of connections that are made 
to facilitate desiring-production can be largely virtual in nature. There is no need for a real product, or even for real people producing something, in order for value to be created. Companies such as Facebook and YouTube trade on their "cultural value" and do not seem to need mediation through commodity production. Since this "cultural value" is an emergent phenomenon, there comes a time when these start-up companies are bought by larger corporations, making their owners substantial profits, which merely starts the cycle of seeking surplus value all over again.

Could this view of corporations as dispensable profit-making machines have underpinned the downfall of big corporations like Enron and the broader global financial crisis a number of years later? Their executives did seem to be driven more by the need to uphold the perception of profit-making capacity than with the creation of real commodity value. Sadly, even if one did believe that corporations are mere profit-generating machines with no value in and of itself, their loss unfortunately comes at a cost to real individual lives. Capitalism ties individuals to this machinic conglomorate and essentially makes their bodies and desires part of the machinic operations of capitalism.

For corporations to be responsible in the sense of being accountable agents, there has to be some recognition of their capacity for participating in the coding and recoding of the desiring-production operative in the capitalist environment. An acknowledgment of the fact that all business decisions are value-laden lies at the heart of this. The process of valuation is ongoing, and within corporations, this is clearly not necessarily centered on "moral values". Instead it entails the pragmatic emergence of value priorities that have to be scrutinized for its moral implications. For instance, if one studies the budget of a corporation, it becomes clear what its value priorities are. Corporations spend money on 


\section{5}

things they care about, i.e. items and activities that they value. If more money is spent on marketing than on research and training, this speaks to its value-priorities. Similarly, a performance management system signals to employees what is valued in the corporation. Over time, value priorities may shift and this will be reflected in what people are rewarded for. In the recent mortgage crisis, it became clear that various types of incentive schemes played a large part in undermining a concern for the end-user of the mortgage system, while prime value was placed on short-term profit gains. What was valued only became clear after the fact, when the damage was done. Accountability means acknowledging these emergent value priorities and re-evaluating it on an ongoing basis. It means scrutinizing the spontaneous process of valuation as it emerges in the corporations' interactions with its stakeholders, environment, resources and contingent challenges. This is always already occurring. Accountability means acknowledging that any kind of valuation has moral implications. We cannot gloss over these implications by mindlessly subscribing to certain capitalist axioms, like the unquestioned belief in growth and development.

But how can this process of revaluation be procured? In the next section, we unpack the further assumptions around identity and agency that impact on the area of responsible management. If corporations and their agents are to be engaged in "responsible management", we need to believe that their revaluation will not only be based on corporate self-interest. It is here, that the reconsideration of responsibility as a trait and as a role responsibility becomes important.

\section{RESPONSIBILITY AS A TRAIT AND ROLE RESPONSIBILITY:}


Responsibility as a character trait of an individual manager has been an important research topic within the Business Ethics literature. In many cases, this discussion focuses on how the responsible individual manager can resist the corporation's unethical demands. A study of the contaminating effects of corporate culture on individual moral agency involved scrutinizing the effects of power on individuals within corporations and the impact of bureaucracy on the individual's morality. As Card (2005) argues, one can even witness the abdication or erosion of individual moral responsibility within corporate contexts.

Scholars have argued that the power that corporations exert over individuals involve more than intentional and overt behavioral direction. Instead, it extends to the structural factors within a tacit system of beliefs and values that are operative within the organization. Furthermore, a Foucaultian analysis of disciplinary power unveils the effects of regimentation, the structuring of institutional space and internalized control on individual behavior (Hiley, 1987). Also drawing on Foucault, Ibarrro-Colado, Clegg, Rhodes, and Kornberger (2006, p.52) argue for understanding what they call the "governmental conjecture between self, others and organizations". The intricate interaction of the self with the power exerted by other individuals and institutions makes the formation of a self who can act "responsibly" a matter of much complexity.

De Cremer, Mayer \& Schminke (2010) argue for a behavioral ethics approach to understanding the complex mix between individual and contextual factors that conspire to allow individuals to engage in bad behavior. They come to the conclusion that a complex array of the personal characteristics of individuals and the groups to which they belong influence their moral behavior. Werhane (1989) however insists that assigning 


\section{7}

corporations agency and insisting on corporate responsibility should not mean that individuals should not maintain their responsibility and accountability for wrongdoing as well.

Much of the Business Ethics literature also focuses on how individuals can be best prepared to act responsibly in the face of complex sets of pressures. For instance, Nielsen (1998) has argued that this preparation includes a combination of cognitive understanding, affective concern and effective political method, which he combines in his action-learning model. Does this mean that we are once again back to assigning individuals the role of ensuring that business is done ethically? Should we look to strengthen individuals' understanding of their roles and legally binding fiduciary duties and aid them in resisting the corrupting pressures that the corporate environment subjects them too?

What has become increasingly important in the field of Business Ethics, is the contention that corporations should take great care in creating an environment conducive to responsible management. In fact, in the literature around the interaction between individuals and their corporate contexts, it seems as if there is a belief that certain corporate "traits" are required to ensure the ethical behavior of the individuals associated with it. In most cases, these traits are referred to as the corporation's "culture". The question that is often posed is whether ethical failures in corporations are the result of bad apples (unethical individuals) or bad barrels (corrupting organizational structures). It also led to a plethora of articles debating the benefits of a values-driven approach to organizational culture, versus a compliance-driven orientation stipulating clear rules and procedures. Linda Trevino (2010) argues that the two approaches are not mutually 
exclusive and that successful ethics management programs often employ a combination of both values-driven cultural interventions with a strong compliance orientation.

This belief that corporate culture can either foster or hamper ethical behavior, has led to a myriad of initiatives focused on the management of corporate culture, also referred to as "ethics management". Within certain contexts, like the US, corporations have even been legally enticed to proactively manage their organizational cultures in order to prevent ethical violations. In the US, the most prominent initiative in this regard is the US Federal Sentencing Guidelines for Corporations. Within the Federal Sentencing Guidelines for Corporations, seven steps are prescribed that should be taken in the establishment of an ethics and compliance program (Driscoll and Hoffman, 1999). ${ }^{1}$ As it happened, experience soon showed that a program in and of itself has little power to curb misconduct. The spate of corporate scandals that occurred in the early 2000's compelled the Federal Sentencing Commission to take stock of what seemed to be the failure of many corporate ethics programs. In 2004 they revised the Guidelines and significantly elaborated on the criteria that ethics programs in corporations had to meet. They also assigned significantly more responsibility to the governing authority (i.e. the Board of Directors) and executive leadership of an organization in overseeing the ethics program. An important new provision was that an organization has to show that it had promoted "an organizational culture that encourages ethical conduct and a commitment to compliance with the law." This has led to renewed interest in the issue of managing corporate culture in the field of Business Ethics (Petry, 2005).

Many scholars have however questioned the capacity of corporations for moral agency. One of the most prominent objections against assigning corporations moral 
19

agency draws on Emmanuel Levinas' analysis of what moral responsibility in fact requires. For instance, by drawing on Levinas, Bevan and Corvellec (2007) make it clear that it is impossible for corporations to be "moral persons" in the way that flesh and blood human beings are. Another objection against the way in which corporations were assigned agency in Business Ethics, focuses on the way in which the corporate agency construct is modeled on the notion of the isolated, self-interested individual. As Roberts (2003, p. 251) argues, from this atomistic perspective, social relations are seen as fundamentally competitive, and any ethical responsibility hence becomes a matter of utilitarian trade-offs.

A more rigorous analysis of the role that corporations can play in procuring responsible actions within society seems long overdue. Since sophisticated agency constructs and legal developments have now for all extents and purposes rendered corporations "persons" with similar rights, many business ethicists argue for assigning them corresponding responsibilities. These are attempts at a more rigorous definition of how corporations should function as "citizens" in a global context (Moon, Crane \& Matten 2005, p. 450). Crane, Matten and Moon (2004, p. 110-114) contend that corporations are involved in developmental democracy to the extent that they safeguard certain civil and social rights of other citizens. This has been particularly important when multi-national corporations operate in countries guilty of human rights abuses (e.g. China and Apartheid South Africa), and in developing countries where the state cannot adequately protect and deliver certain social rights, such as healthcare, education and infrastructure. 
Critics of the corporate citizenship approach argue that the conflation between the notion of a legal "person" and a public citizen should not be tolerated. Corporations don't have bodies that can get hurt, age and die like those of human citizens in society. They don't vote for governments like individual human citizens do. Add to this the fact that many multinational corporations operate all over the world, and one is left with the vague notion of multinational corporations being "world citizens". Banerjee (2006) points out that even though the law can recognize the metaphoric personhood of a corporation, it is by no means easy to assign corresponding responsibilities to them. What we are left with are "persons" who have lots of rights, but no real responsibilities. If we are going to assign to corporations the functions of government, how can we make sure that they will administer these fairly and to the benefit of all in society?

Crane, Matten \& Moon (2004) argue that there are various mechanisms through which stakeholders can participate in the governance of corporations, or exert pressure on them. Within corporations there may however be more of a concern for protecting the rights of those stakeholders who have a direct impact on their operations, i.e. customers, employees, and suppliers. All these parties are economically empowered in some way they can influence the corporation by withholding their investment, spending power, or production power. The question that remains is how we can be sure that the corporation will protect the rights of economically disadvantaged groups, like the unemployed or the poor who don't have spending power. How can we be sure that corporations will be trustworthy custodians of certain common goods, like water, air and natural resources that belong to all in society? 
21

Despite claims by Crane et al that the new corporate citizenship model (NCC) that they propose is descriptive, and value-neutral, Jones and Haigh have accused them of betraying a clear neoliberal prejudice and refusing to acknowledge that corporations do not always operate in the best interests of society (Jones and Haigh, 2007, p. 68). Furthermore, even if they wanted to serve societal interests, it is not easily conceivable that corporate structures will be able to accommodate participatory decision-making models that take pluralistic interests into account. Hence, corporate "decisions" are not sufficiently safeguarded by democratic processes, as most governments can at least claim to be.

Other objections to the idea that corporations can be citizens draw out the implications that this will have in practice. Why would corporate boards agree to take on the obligation to act as administrators of citizenship rights? Hans van Oosterhout (2005, p. 680) argued that they would do so because of the concomitant rights that they can claim in the process. He believes that there would be those who advocate that corporations should attain some fundamental human rights, like protection against arbitrary interference and expropriation by governments. Corporations would also lay claim to rights that give states and other intra- and international entities privileged status under national and international law. This will have an impact on the status and legal subjectivity of corporations under international law. It would also allow corporations to invoke these rights against real human beings.

How can we make sure that corporation boards will use the corporation's status as artificial persons and the rights that this affords them for good rather than evil? It becomes clear that relying on an individual successfully playing his/ her role as agent of a 
principal, or fulfilling some legal requirement in terms of compliance will not suffice in contemporary corporate contexts. How should we then think about responsible management?

The problem with the kind of ontology that underpins most strategies towards responsible management is two-fold. In the first place, it emphasizes the moral identity of individuals and corporations instead of taking seriously the multiplicity that is characteristic of capitalist desiring-production. Secondly, it assumes that responsible management can be procured by reminding executives or Boards of their fiduciary duties and threatening legal sanction if these fail. What we have resorted to is an approach to responsible management that is overly reliant on legal sanctions and out of touch with what moral responsiveness requires in the face of the complex ethical challenges we face in contemporary business environments.

If we take Deleuze seriously, we may come to consider some of this more conventional understanding of "responsibility" in a more critical light. Deleuze (2006) explains that there are forms of responsibility that undermine the autonomy of the individual to be responsive. He draws on Nietzsche's analysis of reactive forces to indicate that a certain type of responsibility, such as that which belongs to a role, or arises out of guilt, in fact stimulates a very minimalist concern for what he calls "responsibilitydebt", that is procured by means of training and selection. The kind of individual whose sense of responsibility is defined in and through this debt loses power over him/ herself and hence loses the capacity for responsiveness. Deleuze argues that though this is the means by which culture develops responsibility, this should not be confused with the desired end of this process, which is the sovereign, free individual. In the context of 
23

corporate governance, a sovereign person does not see his/ her responsibility as a kind of

role to play as agent of a principal, nor in terms of a law that holds him/ her accountable, but as the capacity to respond to a specific situation in an autonomous fashion. "The right to make promises is only possible if one is no longer responsible to any tribunal" (Deleuze, 2006, p.137). This flies in the face of corporations' preoccupation with legal compliance, minimalist rule-obedience and their tendency to outsource their moral responsibilities towards their stakeholders. It also requires a sense of "citizenship" responsibilities that goes beyond a discussion of the "rights" that corporations have.

What seems to be at stake here is the maintenance of a responsiveness that goes beyond mere legal status, legal obligation or legal sanction. From this perspective, one may even argue that too much of the responsible management discourse is preoccupied with what can and should be established in legal terms, especially in the United States. Responsible management should not be concerned with what individuals or corporations are in legal terms, but instead about what they are becoming in and through their valuations, as enacted in and through their everyday practices and habits. In order to fully appreciate the implications of this for responsible management, we have to reconsider how moral "decisions" and actions emerge in corporate settings.

\section{RESPONSIBILITY AS THE CAPACITY FOR RESPONSIVENESS:}

From the above it becomes clear that current debates around corporate agency and individual moral agency within corporations display a number of assumptions that call for philosophical interrogation. Much of agency theory tends to assume that corporations, 
and the individuals that operate within them, have distinct identities, or character traits, that allow them to make deliberate moral decisions and to act accordingly. We saw that in the case of corporations, these "identities" are described in terms of "organizational cultures". In terms of individuals, much attention is paid to the fiduciary duties that executives have, and the development of their personal integrity through various kinds of ethics training sessions and awareness raising programs.

However, if we take the fluid process of desiring-production into account, we may have to question whether responsibility entails a deliberate decision-making process of individuals with integrity. Nor can we easily assume that it entails some decision-process that is guided by a culture of strict ethical compliance. If we take Deleuze and Guattari's perspectives on how agency comes into existence seriously, a new understanding of responsible management may be necessary.

We can trace the emergence of this kind of "agency" by following Deleuze and Guattari's description of how ordering processes create certain propensities within a system, so much so that certain behaviors become salient, and other possibilities unlikely. In fact, Deleuze and Guattari's description of the functioning of territorial assemblages can help us to understand the interaction between corporate institutions and practices and the agency of those within it.

The development of Deleuze and Guattari's vocabulary regarding agency is interesting in this regard. Initially, in Anti-Oedipus, they use the notion of 'desiringproduction' to describe the creation of coded territories. Later in their oeuvre, these references are replaced by the idea of "assemblage" / "agencement". The notion of "assemblage", which is used to describe the French concept of agencement, makes it 
25

clear that the territories created through the processes of desiring production function as "systems of habit", which in turn allows us to experience a sense of agency. These assemblages allow for agencing (i.e. the verb form of agency). Deleuze and Guattari (1987, p. 90) describe "agencement" as follows: "We think the material or machinic aspect of an assemblage relates not to the production of goods but rather to a precise state of intermingling of bodies in a society, including all the attractions and repulsions, sympathies and antipathies, alterations, amalgamations, penetrations, and expansions that affect bodies of all kinds in their relations to one another."

This brings Deleuze and Guattari to conclude that a society is defined by its amalgamations, not by its tools or goods. As such, "agency" becomes the side-product of all the interactions that corporations are involved in, and in fact, depends on these interactions. From this perspective, we have call into question the assumption of deliberate decision-making processes that underpin so much of our discussions around agency and accountability.

Our desiring-production is shaping us through what Deleuze (1994, p.74) calls "passive syntheses" which create our capacity for imagination, for intuiting the next step or the direction we should follow. By definition, a passive synthesis is something that we do not actively devise. It is something that happens in the mind rather than through conscious mindful activity. These passive syntheses constitute our habit of living, and in a very real sense, we are our habits, as they develop over time. We are our habits, not only as minds, but also, very importantly, as bodies. In Deleuze's (1994, p.74) description we are "organically composed" of a thousand of passive syntheses. I would 
therefore argue that if we are to become "responsible managers", it would because we have been and continue to be habitually predisposed towards moral responsiveness.

The "responsible manager" does not have a clear-cut moral identity, but instead displays a contemplative soul that allows a sense of identity to emerge over time. What we do after we habitually act in the world, is to contemplate how exactly we came to certain conclusions or why we took certain actions, and it is this "contemplation" that allows us to construct an "identity". As Deleuze (1994, p. 71) explains, memory and understanding are superimposed upon and supported by the passive syntheses of the imagination. The "agent" is something that arises as a side-product of certain practices and habits that we become part of due to these passive syntheses.

Therefore, if the "responsible agent" emerges in and through contemplation, he/she does not exist before this contemplation takes place. Instead, "responsible management" is an emergent part of an ongoing set of connections and responses to connections. Managers cannot have the kind of identity that would make "responsibility" possible, at least not, responsibility as it was traditionally conceived. Instead, the kind of responsibility that Deleuzian agency would allow for, would require a unique, individual response to a specific situation that emerges in and through the individual's immersion in events and connections.

An appreciation of the passive syntheses that inform our capacity for agency makes it clear that there are many risks to responsible management that do not seem easy to resolve. The corporate "assemblage" that emerges over time includes tacit, unspoken beliefs of which individuals are often not conscious, but that can still have an influence on their behavior. Within this context, individuals can easily become incapable of 
27

dissenting from the beliefs and habits of the group as it has become sedimented over time. If the corporate environment's coded reality is one of amoral or even immoral behavior, the individual will not be able to explore ethical possibilities. Individuals who operate in certain fixed roles for a long time and internalize the practices, habits, beliefs of that role, may indeed find it hard to think beyond those frames of reference.

In dealing with this reality, many of the trusted "ethics management" strategies will inevitably come up short (Painter-Morland, 2008). For instance, trying to come up with an "integrity" strategy that will train individuals in the application of certain core values, will have little effect in dealing with the multiplicities that are part of desiringproduction that is always at work in organizations. The lines of influence between organizational dynamics and employees' moral sensibilities are not one-directional. It involves a multi-directional flow of verbal, visceral and mental signals about what is valued by and expected from the organization's employees and agents. In order to enable responsibility, the more fluid relational dynamics that emerge between individuals, groups and institutions have to be taken into account.

One would also have to consider what passive syntheses entail for "corporate agents" who do not have habituated bodies in the sense that human beings do. How do corporate habits manifest itself in an often entirely disembodied environment? One may draw on Foucault to argue that corporations discipline the individual bodies of its stakeholders, often with detrimental consequences (see in this regard the work of Randall and Munro, 2010, p. 1490), but is something collective also at stake? It is easy to resort to the literature on "corporate culture" here, but this may not suffice. In many ways, even the discourse on corporate culture has become disembodied, emphasizing shared values 
and beliefs, and relying on vague corporate value statements. It may be important to investigate just how the body has been systematically removed or undermined in corporate cultures where virtual communication and interaction, speed and distance make embodied connection impossible or infrequent. It may be precisely this disembodied reality that forecloses the possibility of "responsible management".

This does however not mean that change within organizations is impossible. Quite the contrary is true. If the multiplicity of desiring-production is acknowledged, new forms of agency become more likely. However, to call this agency in the strict sense of the word may be a bit of a misnomer. What it is instead in a form of "agencing" - i.e. the verb-form of agency. This can only occur when individuals are no longer perceived as "functionaries" or as "tools" with neat identities within the organization. In order to conceive of responsibility in different terms, we need to find ways of drawing on the multiplicity of which Deleuze and Guattari's reading of entities and individuals make us aware and seek out possibilities to make this multiplicity an asset in responsible management.

Individuals are in and of themselves multiplicities of force, and as such, they are capable of "agencing" that is unique and surprising. But this only becomes possible if we can allow individuals to find creative escapes from the corporate territories that may have created axiomatic patterns and paths shaping the passive syntheses that inform their agencing. This demands two types of activity: the first is a critical scrutiny of the emergence of certain patterns of behaviors, beliefs and orientations that shape our agency in organizations; the second entails courageous experimentation with the possibility that things could be done differently. The kind of questioning that signals the existence of a 
29

responsive agent can only emerge as a result of an intense engagement with people, events, and the environment. This cannot be done at arms-length, but instead requires real participation in the messiness of everyday-life. Deleuze and Guattari offer us multiple concepts that may allow us to explore this possibility. We cannot discuss them all here, but two notions seem particularly promising in the context our discussions of responsible management.

The first is the idea of a body without organs $(\mathrm{BwO})$. A BwO refers to a plane of consistency where the multiplicities inherent in desiring flows are freed from mechanistic or organismic functions, and can take on new shapes (Deleuze \& Guattari, 1987, p. 14966). Matter, energy, desire must be able to flow without centralized or hierarchical control. So, instead of being assigned specific roles, individuals and corporations should explore multiple different possibilities, which have not yet been coded. This would imply that something like "moral responsiveness" can only emerge spontaneously, without any fixed programming. ${ }^{3}$ In fact, to be capable of an individual moral response at all, desiring production must be allowed to escape coded possibilities. What happens to the notion of "identity" in this process? Deleuze and Guattari explain that the $\mathrm{BwO}$ is not "me", nor is it something that is a product of individual ingenuity. Instead the "me" is on it, or whatever "I" am, it is constantly changing form, crossing thresholds, exploring possibilities. Responsibility, conceived from this point of view, becomes an ongoing experimentation in responsiveness.

In practical terms, exploring the possibility of the $\mathrm{BwO}$ in corporate settings will require of individuals to go beyond their assigned role-responsibility within the corporation. Whereas a strict circumscription of fiduciary duties could allow a 
functionary to pass the buck saying: "This issue falls outside of my duties and responsibilities", real moral responsiveness poses a broader challenge. Contingent challenges that emerge as part of the corporation's engagement with specific stakeholders and the environment, demand a response that cannot be calculated, anticipated or programmed in advance, but instead, requires imagination, creativity and passion.

The calculated aloofness of the transcendental subject will not serve us here. Instead, a responsiveness that dares to care is required. As such, it is plea to go beyond abstract rights and duties, towards a sense of embodied concern and investment. An example of a project that may be seen as an experiment in exposing future leaders to just this kind of engagement, is PricewaterhouseCooper's Responsible Leadership initiative, called the Ulysses project (Pless and Schneider, 2006, p.213). The project was started to send future leaders at PwC into developing countries to assist local NGOs with whatever projects they were pursuing. Clearly, the idea is to take these corporate executives out of their comfort zone, to expose them to the contextual challenges of an unfamiliar setting, and to challenge these executives to discover ways to help the local population. One of these executives, named James ${ }^{4}$, reported the following:

"I have learnt so much in the last few weeks. I have learnt about the public and third sectors, how they work and how they don't, but that is just facts. I have learnt about others in society and the bad things that happen. I have discovered within myself a desire to apply some social justice. I am going to go on making a difference and keep discovering. I have discovered compassion. [Reading this I also discover that I can sound like an evangelical git, but hey, it's my last day.]"

It seems clear that James have experimented with aspects of himself that he was unaware of, discovering a deeper sense of concern for others, which enables him to now respond in new ways. James was not given a set of principles on a sheet of paper, nor was he reminded of his fiduciary duties - instead, he was exposed to the intermingling of 
31

bodies, to new amalgamations, attractions, repulsions, which enabled him to become more responsive.

A second concept that may be helpful in the context of responsible management is that of "lines of flight" (Deleuze and Guattari, 1987, p. 55). Lines of flight are vectors of both de-territorializing and re-territorializing. There are two kinds of "lines of flight", relative lines of flight and absolute lines of flight. Bonta and Protevi provide a helpful description of lines of flight as "vectors of freedom", or at least "freedom-from".

Sometimes freedom is procured by finding safety in a set of practices, habits and beliefs that offer at least some immediate security and acceptance, at other times it entails a more radical departure from any related practice or pattern. A relative line of flight is a move towards a predetermined attractor. That is, it means that new possibilities were explored, but in line with certain existing orders. Within the CSR environment, a "relative line of flight" may mean that a corporation could decide to embark on a sustainability initiative, but only if it is clear that it would also yield some financial benefits. The predetermined attractor of profit-generation thus remains intact, even though new practices may be experimented with and previous ways of doing things discontinued.

This does however not mean that a more radical departure from organizational "business as usual" is not also sometimes required. Here, the employment of Deleuze and Guattari's "absolute line of flight" may become necessary. An absolute line of flight occurs when there is an absolute de-territorialization of the current pattern, and new attractors, bifurcators and patterns have to emerge. One may for instance think of the actions of a whistleblower, such as Cynthia Cooper, as an absolute line of flight, which 
entailed her eventual departure from the organization she worked for, WorldCom, and precipitating its subsequent filing for bankruptcy. Cynthia Cooper was the Vice President of Internal Audit at WorldCom when she discovered their massive $\$ 3.8$ billion fraud. Because of the institutional resistance she encountered, she and her team of accountants had to work secretly at night to unravel the deceit and to expose the wrongdoing.

It could be that the demise of a corrupt organization, at least in its current form, is precisely what responsible management may require in certain situations. In the case of WorldCom, the company eventually emerged out of bankruptcy and merged with MCI, an American subsidiary of Verizon Communications, but the case did raise a lot of red flags in terms of what was possible in terms of corporate misconduct in the United States. The response was enhanced legislation, but the question that remains is whether this really increased responsible management. Based on our earlier analysis, we can argue that legal measures will most probably not yield the kind of responsibility that is required in corporate contexts, as it can at best yield reactive responsibility.

One may also consider whether some organizations close off the possibility of "lines of flight" because of processes of conjunction and overcoding. Overcoding can take many shapes, and we may want to consider what it could mean in corporate terms. For instance, it is well known that WorldCom, Enron and other powerful business empires grew very quickly because of their aggressive takeovers of smaller companies. The question is what remains of moral responsiveness in contexts where large bureaucracies create fixed segments, rigid hierarchies and mechanistic processes. In such contexts, it is inevitable that flows of energy and effort are directed at axiomatic business purposes, which remain unquestioned truths. If we want to rethink "responsible 
33

management", we may need to cultivate certain practices of questioning, critique and resistance. For instance, we have to find opportunities to stimulate dissent, and to engage in criticism of "the way we do things around here". One such an example that comes to mind is the one that Jerry Porras and his colleagues refer to in their book "Success Built to last" (2006). They discuss Commerce Bank's practice of challenging employees to regularly come up with at least one stupid rule to kill. This exercise stimulates a consideration of what exactly rules attempt to protect, and acknowledges that these value priorities may shift over time. In this case, one would describe this as a relative line of flight, as it maintains the central business purpose and reconsider values in the light of this purpose.

A radical line of flight may in fact require a more serious reconsideration of whether certain business purposes are still acceptable. For instance, if a profitable product continually proves to have harmful health effects or undermines employee well-being, should there not be some serious consideration of its potential termination? If certain products or services, or even entire corporations, no longer serve life-affirming purposes, should we not suggest a kind of "corporate suicide"?". Be it as it may, the kind of responsible management advocated here requires at the very least some serious consideration regarding a corporation's continued right to exist.

\section{CONCLUSION:}

In this paper, we tracked the emergence of certain ideas around responsibility in the Business Ethics literature. Our analysis started with a discussion of responsibility as accountability, and proceeded to discuss responsibility as trait or role responsibility. It 
became clear that our understanding of responsibility as a trait, as accountability or as role-responsibility is all built on identity constructs that do not reflect the real nature of capitalist entities, nor does it accurately describe how agency operates. Deleuze and Guattari allowed us to see that what escapes this analysis is the broader processes of desiring-production that take on a certain form within the capitalist system. When we understand how desiring-production functions, we see that the "identity" that we assign to both persons and corporations may in fact belie the multiplicity of flows and desires that are at work within the complex corporate environment. In fact, "identity" may just be the emergent effect of the structuring, de-structuring and restructuring that takes place as individuals and organizations move through the various cycles and flows that is part of our existence in the world.

These insights challenge us to embrace the material, embodied realities from which our conceptions of "agency" emerge. It provides us with a more complex, and admittedly a much more messy picture of human motivation and normative orientation. The implications of this understanding of human agency should therefore precipitate a rethinking of our attempts at enhancing the moral responsiveness of individuals in the workplace. For instance, instead of conducting annual online ethics training sessions, we may have to consider engaging people's bodies and their experiences of their material realities. The objection would of course be that this proposal is not practical, that it is too expensive and time-consuming to consider such alternatives. It is clear that this objection suffers from a preoccupation with convenience and cost-effectiveness, rather than displaying real commitment to ethics. What is however even more disconcerting, is that it displays a belief that ethics somehow lies beyond everyday business practices, as a 
35

separate "budget item" or "compliance exercise". From what we saw above, moral agency emerges through everyday practices and engagements with others. What Business Ethicists have to figure out, is how to infuse these everyday occurrences with ethical reflection.

The insights that we gained around responsibility also challenge us to think about how we talk about accountability and how this translates into punishments and encouragements. A relational understanding of accountability poses distinct legal and compliance challenges, that need to be thought through from a regulatory perspective. But beyond regulation, organizational policies and procedures must also be rethought. We need codes and structure, but sometimes when these codes become axiomatic, they cut off the flow that allows us to be morally responsive. These structures are not always external, or based on institutional constraints, and can therefore not be managed in a demand-and-control fashion. Often, there are unconscious desiring-flows within our own bodies and institutions that allow for the emergence of agency, or foreclose it. We therefore require structures and points of orientation that signal important value commitments, while remaining open to reinterpretation and redefinition. It is in and through the process of challenging these structures on an ongoing basis, and questioning their validity in changing circumstances that ongoing moral responsiveness may emerge.

The challenge that confronts us as we make our way in the world is to seek the life-affirming possibilities that lie within and beyond the various structures that we operate within. This means that we will in some cases have to seek escape routes, or lines of flight, in Deleuze and Guattari's vocabulary. Sometimes we will find our way into other, similar structures, and at other times, we may be confronted with more radical 
changes. It is in being open to the possibility of these subtle, and sometimes even radical changes that responsibility resides. This may entail a deliberate disruption of "business as usual", and as such, it may be difficult to convince business executives of this approach. However, in an environment of fast paced change and complex dynamics, it may be precisely this willingness to head off the beaten path that may become the creative lifeblood of contemporary organizations. Part of this process is a commitment to find new avenues for our desiring-production through very embodied, material experiments and visceral engagements with others and with the animate and inanimate environment. What may emerge as a side-product of these excursions, is the kind of agency that is capable of ongoing moral responsiveness. This may indeed be a different understanding of "responsibility", but one that may be worthwhile pursuing if we want to deal with contemporary ethical challenges in corporate environments.

\section{References:}

Banerjee, S.B.: 2007, The problem with corporate social responsibility. In Clegg, S. \& Rhodes, C (eds): Management Ethics: Contemporary Contexts, (London, Routledge), pp. $55-76$

Banerjee, S.B.: 2006, Corporate Social Responsibility: The Good, The Bad and The Ugly, (Edward Elgar Publishing)

Bauman, Z.: 1993, Postmodern Ethics, (London, Wiley-Blackwell) 
37

Boholm, Åsa \& Corvellec Hervé.: 2011, A relational theory of risk. Journal of Risk Research, 14(2), $175-190$.

Bevan, D. \& Corvellec, H.: 2007, 'The Impossibility of Corporate Ethics: For a Levinasian Approach to Management Ethics', Business Ethics: A European Review, 16(3), 208-219.

Bonta, M. and Protevi, J.: 2004) Deleuze and Geophilosophy. A Guide and Glossary, (Edinburgh University Press, Edinburgh)

Buchanan, I.: 2008, Deleuze and Guattari’s Anti Oedipus. A Reader's Guide, (Continuum, New York) p.39

Card, R.F.: 2005, 'Individual Responsibility in Corporate Contexts', Journal of Business Ethics, 62, 397-405.

Clegg, S.R. and Rhodes, C. Eds.: 2006, Management Ethics - Contemporary Contexts, (London: Routledge)

Crane, A, Matten, D. and Moon, J.: 2004, 'Stakeholders as Citizens? Rethinking Rights, Participation and Democracy', Journal of Business Ethics 53, 107-122.

De Cremer, D.; M Mayer, D.; Schminke, M.: 2010, 'Guest Editors' Introduction. On Understanding Ethical Behavior and Decision Making: A Behavioral Ethics Approach', Business Ethics Quarterly, 20(1), 1-6.

Deleuze, G.: 2006 /1983, Nietzsche and Philosophy. Translated by Hugh Tomlinson, (Columbia University Press, New York)

Deleuze, G.: 1994, Difference and Repetition. Translated by Paul Patton, (Columbia University Press, New York) 
Deleuze, G. \& Guattari, F.: 1992/ 1983, Anti-Oedipus. Capitalism and Schizophrenia Translated by Hurley, R; Seem, M. and Lane, H.R., (University of Minnesota Press, Minneapolis)

Deleuze, G. \& Guattari, F.: 2007/1987, A Thousand Plateaus. Capitalism and Schizophrenia Translated by Brian Massumi, (University of Minnesota Press, London)

Freeman, E.: 1984, Strategic Management A Stakeholder Approach. Pitman Publishing Erokovic, L.: 2008, “Corporate Governance” In: SAGE Encyclopedia of Business and Society (Sage, London), pp. 471-480.

Freeman, E.R. Wicks, A. Harrison, J. Parmar B. and de Colle, S.: 2010, Stakeholder Theory: The State of The Art, (Cambridge, Cambridge University Press)

French, Peter A.: 1984, Collective and Corporate Responsibility, (Columbia University Press, New York)

French, Peter A.: 1995, Corporate Ethics, (Harcourt Brace, Fort Worth)

Friedman, M.: 1970, 'The Social Responsibility of Business is to Increase its Profits', The New York Times Magazine, September 13, 1970

Driscoll, D-M and Hoffman, W. M.: 1999. Ethics Matters. How to Implement Valuesdriven Management, (Bentley College Center for Business Ethics, Boston)

Hiley, D.: 1987, 'Power and Values in Corporate Life', Journal of Business Ethics, 6, $343-353,11$

Ibarra-Colado, E.; Clegg, S. R.; Rhodes, C.; Kornberger, M: 2006, 'The Ethics of Managerial Subjectivity', Journal of Business Ethics, 64, 45-55.

Jones, C.; Parker, M. and ten Bos , R.: 2005, For Business Ethics, (Routledge, London) 
JBE Special Issue: Responsible Management Resubmission August 31, 2011

39

Jones, M. T. and Haigh, M.: 2007, 'The Transnational Corporation and New Corporate

Citizenship Theory. A Critical Analysis.' Journal of Corporate Citizenship, 27: 51-69

Message, K.: 2005, The Deleuze Dictionary, Edited by Adrian Parr, (Columbia

University Press, New York)

Matten, D.; Crane, A.; Chapple, W.: 2003, 'Behind the Mask: Revealing the true face of

Corporate Citizenship', Journal of Business Ethics, 45: 110

Moon, J.; Crane, A. and Matten, D.: 2005, 'Can Corporations be Citizens? Corporate

Citizenship as a Metaphor for Business Participation in Society', Business Ethics

Quarterly, 15(3): 429-453.

Nielsen, R. P.: 1998, 'Can ethical character be stimulated and enabled? An actionlearning approach to teaching and learning organization ethics', Business Ethics Quarterly, 8(3), 581-604, 24

Parr, A.: 2005, The Deleuze Dictionary. (Edinburgh, Edinburgh University Press)

Painter-Morland, M.: 2008, Business Ethics as Practice. Ethics as the Everyday Business of Practice, (Cambridge University Press, Cambridge UK)

Painter-Morland, M.: 2010, 'Derrida and Business Ethics: Ethical questioning (and)(or) questioning ethics', Business Ethics: A European Review, Special edition on Derrida and Business Ethics, 9(3): 265-279.

Painter-Morland. M. and Ten Bos, R.: 2011, Business Ethics and Continental Philosophy, (Cambridge, Cambridge University Press)

Parker, M.: 1998, 'Business Ethics and Social Theory: Postmodernizing the Ethical', British Journal of Management, 27-36.

Petry, E.: 2005, 'Assessing Corporate Culture Part 1', Ethikos 18(5) 
Phillips, R.; Freeman, R.E.; Wicks, A.C.: 2003, 'What Stakeholder Theory is Not', Business Ethics Quarterly, 13, 479-502.

Pless, N., \& Schneider, R.; 2006, Towards Developing Responsible Global Leaders: The PwC Ulysses Experience. in: T. Maak and N. Pless (eds), Responsible Leadership, (London, Routledge), pp. 213-226.

Porras, J. Emery, S and Thompson, M. 2006: Success Built to Last: Creating a life that matters, (University of Pennsylvania, Wharton School Publishing)

Power, M: 1998, The Audit Society, (Oxford University Press, Oxford)

Roberts, J.: 2003, 'The Manufacture of Corporate Social Responsibility: Constructing Corporate sensibility', Organization, 10(2), 249-265

Takala, T. and Pallab, P.: 2000, 'Individual, collective and social responsibility of the firm', Business Ethics: A European Review, 9(2), 109-118.

Linda K. Trevino \& Katherine A. Nelson.: 2010, Managing Business Ethics: Straight Talk about How to Do It Right, 5th Edition, (Hoboken NJ, Wiley)

Randall, J. and Munro, I.: 2010, 'Foucault's Care of the Self : A Case from Mental Health Work', Organization Studies, 39(11) : 1485-1504.

Van Oosterhout, H.: 2005, 'Dialogue', Academy of Management Review, 30:4, 677-684.

US Federal Sentencing Commission. US Federal Sentencing Guidelines. http://www.ussc.gov/guidelin.htm.

Werhane, P. H.: 1989, 'Corporate and Individual Moral Responsibility: A reply to Jan Garrett', Journal of Business Ethics, Oct89, 8(10), 821-822.

Werhane, P.H. and Painter-Morland, M.J: 2008, Cutting-edge issues in Business Ethics: Continental challenges to Theory and Practice”, (Dortrecht: Springer) 


\section{1}

\footnotetext{
${ }^{1}$ The Federal Sentencing Guidelines' seven steps include (1) formulating compliance standards and procedures such as a code of conduct or ethics; (2) assigning high-level personnel to provide oversight (e.g., a compliance or ethics officer); (3) taking care when delegating authority; (4) effective communication of standards and procedures (e.g., training); (5) auditing/monitoring systems and reporting mechanisms, whistle-blowing; (6) enforcement of disciplinary mechanisms; and (7) appropriate response after detection

${ }^{2}$ The concept "agencement" stems from the Latin "agens" which means "to direct" or "to put into motion".

${ }^{3}$ This possibility finds further support in the kind of responsibility suggested by Emmanuel Levinas and Zygmunt Bauman.

${ }^{4}$ Comment found on: http://james-pwc-rlp.blogspot.com/. Downloaded on April 1, 2011

${ }^{5}$ See in this regard the PhD research of Ryan Burg, Wharton School of Business, University of Pennsylvania
} 